\title{
Studies on pigs reared on semi-synthetic diets containing no fat, beef tallow or maize oil : husbandry and serum biochemistry
}

\author{
By A. N. HOWARD, Department of Pathology \\ W. M. F. LEAT, Department of Agriculture \\ G. A. GRESHAM, Department of Pathology \\ D. E. BOWYER, Department of Pathology \\ AND E. R. DALTON, Department of Human Ecology \\ University of Cambridge \\ (Received 2 February 1965-Accepted 23 April 1965)
}

Fibrous atherosclerosis is readily produced in the rabbit by semi-synthetic diets containing all the known essential nutrients, and the inclusion of beef tallow in this diet greatly increases the incidence and severity of atherosclerosis (Gresham \& Howard, 1962). The pig, because of its closer anatomical relationship to man, may be more useful than the rabbit for studies of arterial disease. Furthermore, owing to the size of the animal, any diseased tissue may be subjected to chemical analysis. The primary object of the experiment described here was to induce atherosclerotic lesions in the aorta of the pig by dietary means and, in the event of success, to study the diseased artery chemically. Three semi-synthetic diets containing respectively no fat, beef tallow and maize oil were employed; a fourth, a commercial diet, was used as a control.

The exact growth requirement of the pig for linoleic acid is not known, but it is less than $0.1 \%$ of the total dietary calories for growth up to $200 \mathrm{lb}$ live weight (Leat, I962). A secondary object of the experiment was to investigate further the requirements of the pig for essential fatty acids by using a semi-synthetic diet which was virtually deficient in linoleic acid.

This paper is concerned primarily with the husbandry of the animals and with the chemistry of the serums obtained at slaughter. Other papers deal with the pathological effects of the diets (Gresham, Leat, Howard \& Jennings, 1964) and with the carcass composition and fatty acid composition of the depot fat (Leat, Cuthbertson, Howard \& Gresham, 1964).

\section{EXPERIMENTAL}

Animals

Twenty-eight Large White $\times$ Essex piglets comprising hogs and gilts from three litters were weaned at about a month old and divided into four groups of seven. The litters were divided so that the weight and sex distribution of the piglets in each group was approximately the same (Table I). Pigs given the semi-synthetic diets were 
housed in the same animal house but those given the commercial diet were housed separately under different environmental conditions. All were weighed weekly and brought to approximately bacon weight ( $172-196 \mathrm{lb}$ live weight) on their respective diets (see below). At slaughter, blood was collected, defibrinated and centrifuged to obtain the serum. The organs and carcasses were examined at a suitable stage in a bacon factory and samples were taken of body fat, heart, aorta, lungs, kidneys and liver for histological and chemical examination. All samples for chemical analysis were stored at $-20^{\circ}$ until required.

\section{Materials}

Beef tallow (British Oils and Glues Ltd, London) contained $28.8 \%$ palmitic acid, $3.4 \%$ hexadecenoic acid, $24.3 \%$ stearic acid, $35.3 \%$ octadecenoic acid, $0.7 \%$ octadecadienoic acid (total 92.5\%). Maize oil (Loder \& Nicoline Ltd, London) contained $12.0 \%$ palmitic acid, $0.4 \%$ palmitoleic acid, $2 \cdot 6 \%$ stearic acid, $28.9 \%$ oleic acid and $54.2 \%$ linoleic acid (total $98 \cdot 1 \%$ ). The minor fatty acids are omitted for clarity. The Cellophane used was flaked film (British Cellophane Co., London).

\section{Table 2. Composition (lb) of semi-synthetic and commercial diets given to the pigs}

\begin{tabular}{|c|c|c|c|c|c|}
\hline & $\begin{array}{l}\text { Group I } \\
\text { (no fat) }\end{array}$ & $\begin{array}{c}\text { Group 2 } \\
\text { (beef tallow) }\end{array}$ & $\begin{array}{c}\text { Group 3 } \\
\text { (maize oil) }\end{array}$ & \multicolumn{2}{|c|}{ Group 4 (commercial) } \\
\hline Sucrose* & $65 \cdot 7$ & $43 \cdot 2$ & $43 \cdot 2$ & Barley & $40 \cdot 0$ \\
\hline Cellophane & 100 & $10 \cdot 0$ & $10 \cdot 0$ & Middlings & $28 \cdot 0$ \\
\hline Casein & $20 \%$ & $20 \cdot 0$ & $20 \%$ & Dried skim milk & $30 \cdot 0$ \\
\hline Mineral mixturet & $4 \cdot 0$ & 4.0 & $4 \cdot 0$ & Steamed bone flour & $1 \cdot 0$ \\
\hline Vitamin mixture $\ddagger$ & $0 \cdot 1$ & $O \cdot I$ & 0.1 & Limestone & 0.5 \\
\hline Choline chloride & 0.2 & $0 \cdot 2$ & 0.2 & Salt & 0.5 \\
\hline Fat & $\cdots$ & 10.0 & 10.0 & Vitamin premix & I lb/ton meal \\
\hline Chlortetracycline!! & + & + & + & Aurofac $2 \mathrm{AS}$ & $3 \mathrm{lb} /$ ton meal \\
\hline Total & $100 \cdot 0$ & $87 \cdot 5$ & $87 \cdot 5$ & & \\
\hline $\begin{array}{l}\text { Total digestible } \\
\text { nutrients (calculated) }\end{array}$ & 83 & 83 & 83 & - & $7 I$ \\
\hline
\end{tabular}

* When the pigs had reached $75 \mathrm{lb}$ live weight, sucrose was increased by $5 \mathrm{lb}$ at the expense of casein and barley increased by $\mathrm{Io} \mathrm{lb}$ at the expense of dried skim milk.

$\dagger$ Contained (parts): calcium phosphate $48 \cdot 2$, sodium chloride $5^{\circ} 0$, potassium chloride $25^{\circ} 0$, disodium hydrogen phosphate (anhydrous) 10.5, ferrous sulphate (hydrated) $3 \cdot 0$, magnesium sulphate (hydrated) 8.0, potassium iodide 0.1 , cobalt sulphate (dried) 0.1 , manganese sulphate (anhydrous) 0.02 , copper sulphate (anhydrous) 0.04 , zinc carbonate 0.04 , sodium fluoride 0.005 .

$\mp$ Contained (parts): biotin 0.3 , menaphthone 0.5, thiamine hydrochloride 8.0 , pyridoxine hydrochloride 8.0 , riboflavine 8.0 , folic acid 5.0 , calcium pantothenate 20.0 , nicotinamide $100 \cdot 0$, inositol 100.0 , cyanocobalamin 0.02 , calciferol 0.02 , calcium carbonate 250.0 .

A mixture of vitamins $A, D$ and $E$ in ethanol was added separately to the diet to provide per lb diet up to $50 \mathrm{lb}$ live weight 5000 i.u. vitamin A, I 500 i.u. vitamin D and 5 i.u. vitamin E; and from $50 \mathrm{lb}$ up to $200 \mathrm{lb}$ live weight 2000 i.u. vitamin $A, 500$ i.u. vitamin $D$ and 3 i.u. vitamin $E$.

Calciferol was withdrawn at $120 \mathrm{lb}$ live weight.

$\S$ Containing 4000000 i.u. vitamin $A$ and 1000000 i.u. vitamin D.

II $5 \mathrm{mg}$ chlortetracycline hydrochloride/lb diet until 16 weeks of age.

I Containing $3.6 \mathrm{~g}$ chlortetracycline hydrochloride/lb.

\section{Diets}

The composition of the four diets used in the experiment is shown in Table 2. The diets were given twice daily mixed with water and total water intake was recorded. The weight of food to be given daily to the pigs of group 4 was calculated from the 
mean live weight of each group and was adjusted weekly (Woodman \& Evans, I95I). The pigs of group I were given the same weight of food as those of group 4, and the food intakes of the pigs of groups 2 and 3 were adjusted to be isocaloric with that of group $\mathbf{I}$.

\section{Analysis}

Total faecal lipids. All faeces from each group were collected over a period of 4 days about halfway through the experiment and pooled. A portion was slightly acidified with acetic acid, dried in an oven overnight at $105^{\circ}$, weighed and extracted in a Soxhlet for $6 \mathrm{~h}$ with diethyl ether. Total lipid was then determined by weighing the ether fraction evaporated to dryness.

This method would not estimate volatile fatty acids, but there is little evidence for the presence of acids with chain lengths shorter than twelve carbon atoms (James, Webb \& Kellock, I96I). During the later stages of the experiment, faeces were saponified directly with alcoholic $\mathrm{KOH}$, and the non-saponified lipid was extracted with diethyl ether and discarded. The fatty acids were then liberated with $4 \mathrm{~N}^{-} \mathrm{H}_{2} \mathrm{SO}_{4}$ and extracted with diethyl ether. There was reasonable agreement between the two sets of values, although the second method gave slightly lower values because of the absence of non-saponifiable lipid.

Total cholesterol. Serum ( $\mathrm{r} \mathrm{ml}$ ) was extracted with $20 \mathrm{ml}$ acetone-alcohol ( $\mathrm{I}: \mathrm{I}, \mathrm{v} / \mathrm{v})$. To a portion of the filtrate $(\mathrm{r}-2 \mathrm{ml})$ acetone-alcohol $(\mathrm{I}: \mathrm{I}, \mathrm{v} / \mathrm{v})$ was added up to a volume of $2 \mathrm{ml}$. Hydrolysis and digitonin precipitation were carried out by the method of Sperry $\&$ Webb (1950). The centrifuged and washed digitonide was then dissolved in $6 \mathrm{ml}$ of a solution $\left(0.06 \mathrm{~g}\right.$ anhydrous $\mathrm{FeCl}_{3}$ in $100 \mathrm{ml}$ glacial acetic acid) by heating in a water bath at $80^{\circ}$ for $10 \mathrm{~min}$ by the method of Crawford (1958). Conc. $\mathrm{H}_{2} \mathrm{SO}_{4}(4 \mathrm{ml})$ was then added and, after mixing, the intensity of colour was read in a colorimeter (wavelength $560 \mathrm{~nm}$ ) after $30 \mathrm{~min}$ by the method of Zlatkis, Zak \& Boyle (1953).

Free cholesterol. Cholesterol was separated as the digitonide without hydrolysis of the lipid extract and determined as described above.

Total glycerides. Serum lipids extracted with methanol-chloroform (2:, $\mathrm{v} / \mathrm{v})$ were separated on silicic acid columns (Mallinckrodt Chemical Works) into $(a)$ total glycerides (di-, mono- and tri-glycerides) and cholesterol, and (b) phospholipids by the method of Van Handel \& Zilversmit (1957). The glycerol was determined in fraction (a) by the method of Lambert \& Neish (1950).

Phospholipids. A portion of fraction $(b)$ described above was analysed for lipid phosphorus by the method of Allen (1940), and total phospholipid estimated by multiplying by a factor of 25 . The percentage composition was determined by extracting serum and separating the phospholipids by the method of Marinetti, Erbland \& Kochen (1957), the dried chromatograms being stained by Ponceau Red for estimation as described by Hooghwinkel \& van Niekerk (I960). With this method, three main components separated, namely lecithin, sphingomyelin and lysolecithin. The amount of phosphatidyl ethanolamine was below $5 \%$ and was not included in the estimations. Ponceau Red does not stain phosphatidyl serine.

Fatty acids. The fatty acids of serum and faeces were extracted, analysed by gasliquid chromatography and identified as described previously (Leat, r962, r964). 


\section{Statistical methods}

For each measurement the four groups of pigs were compared in three different ways: ( 1 ) by analysis of variance; (2) by analysis of variance on the logarithms of the measurements; (3) by Kruskal-Wallis one-way analysis of variance (Siegel, 1956).

As in several sets of measurements the variances underlying test I were not equal (the ratio of the largest to the smallest variance in one instance was 467 ), analyses of variance were performed with the natural logarithm of the readings (with the exception of the ratio of $20: 3$ to $20: 4$ since for it several readings were zero). This transformation helped to stabilize the variance in certain instances. Since the validity of the underlying assumption of equal variance was in doubt even in the transformed variable (maximum ratio 34) a Kruskal-Wallis one-way analysis of variance was performed on each set of values because the underlying assumptions for this test are minimal.

For the measurements, for which one of the three tests gave a significant result, the difference between the 'no-fat and beef-tallow' group and the 'maize-oil and commercial' group was investigated. For phospholipids the 'no-fat' group was tested against each of the other groups and the 'beef-tallow' group against the 'maizeoil' group. The differences were investigated by two methods: (a) Welch's approximation to the $t$ test (Kendall, I95I); (b) the median test (Siegel, I956).

Since so many statistical tests have been performed, the usual $5 \%$ significance level has been replaced by one of $I \%$.

\section{RESULTS}

\section{Weight gain}

All pigs grew well throughout the experiment and the live-weight gain of pigs on the semi-synthetic diet was similar to those of the pigs on the commercial diet (Table I). The animals consumed the diet readily with the exception of those given the no-fat diet which appeared less palatable than the other diets. One of the pigs in group I (no fat) died suddenly at about $60 \mathrm{lb}$. On post-mortem examination, the gut was found to be greatly distended and contained a black fluid; the exact cause of death could not be ascertained.

After about 8 weeks, when the animals weighed about $50 \mathrm{lb}$, the pigs in group I began to look unthrifty and showed scaly skins and coarse hair. The severity of these lesions increased until the pigs weighed about $\mathrm{I}_{5} \mathrm{O} \mathrm{lb}$ when an improvement set in, such that by slaughter at about $190 \mathrm{lb}$ live weight the skin appeared quite normal. Pigs given beef tallow or the commercial diet had a normal appearance but those given maize oil had oily skins with coarse hair which had a reddish tinge by the end of the experiment. All pigs on the semi-synthetic diet tended to be weak on their legs, particularly the hind legs. Those in group $\mathrm{I}$ on the no-fat diet were particularly badly affected, with pronounced swelling below the hock for considerable periods during the experiment. All pigs on the semi-synthetic diet were very thirsty, especially the 'no-fat' and 'maize-oil' groups, and drank about 30-40\% more water than those on the commercial diet. 


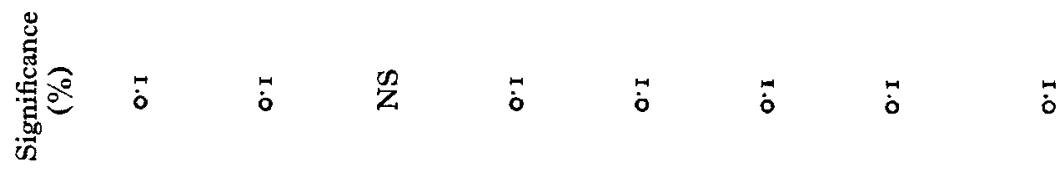

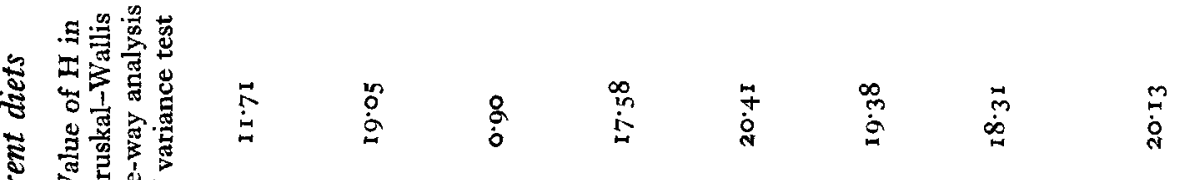

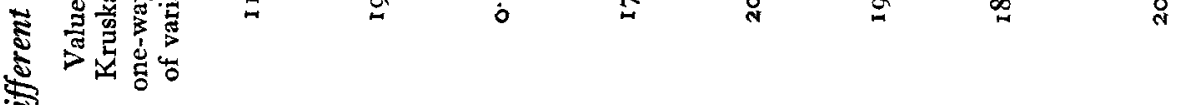

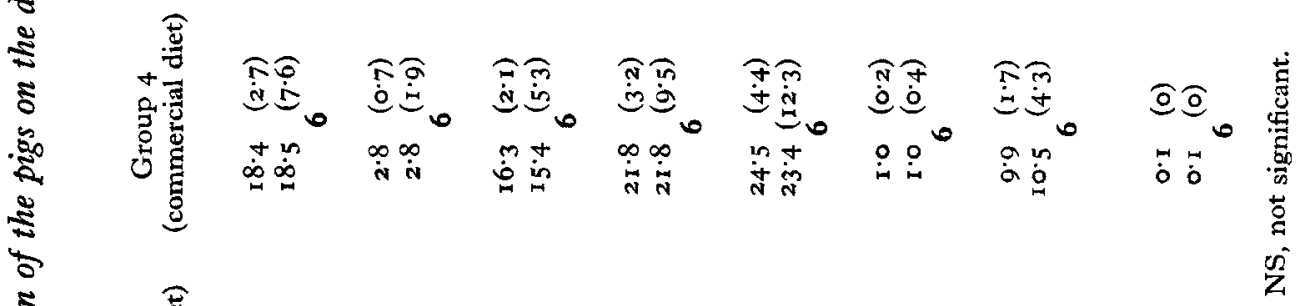

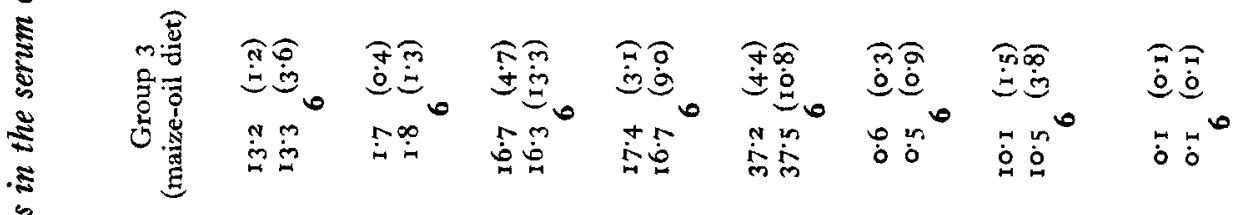

经

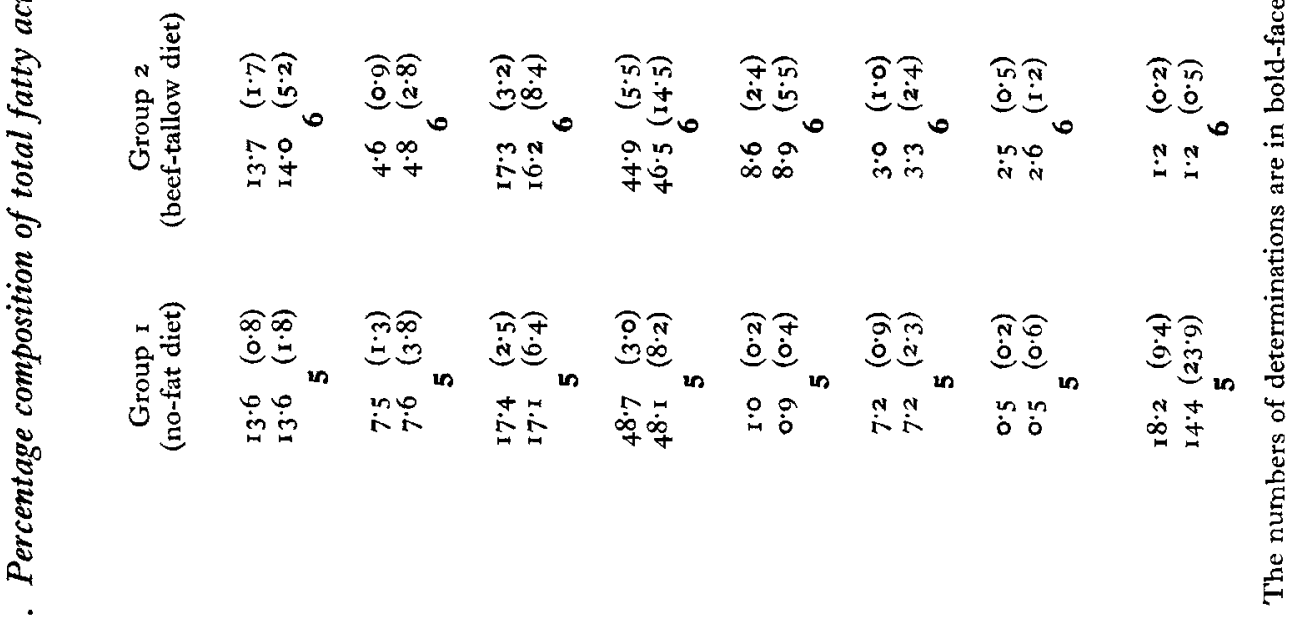

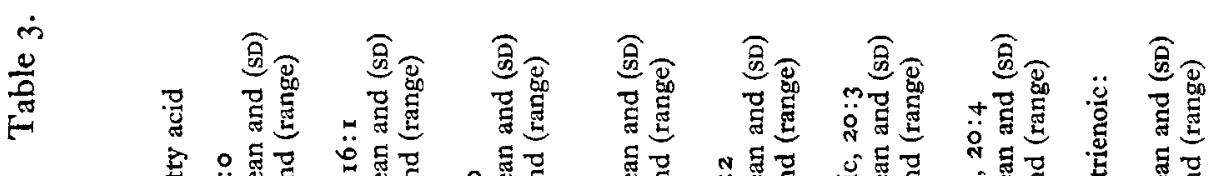

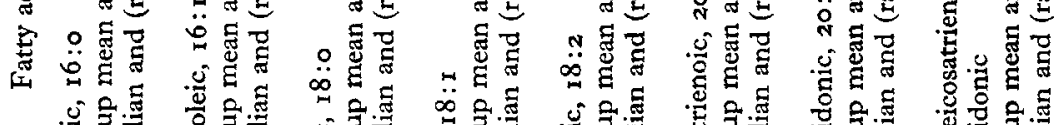

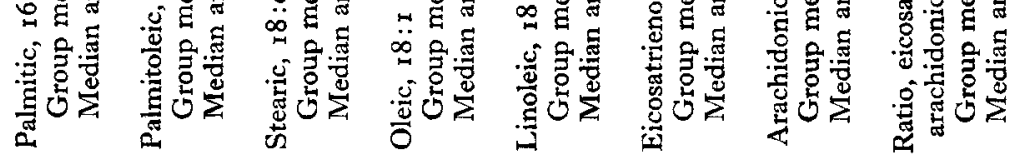




\section{Digestibility of fat in diets}

Analysis of faecal lipids showed that the apparent digestibility of fat in the various diets was $44 \%$ for beef tallow, $79 \%$ for maize oil and $82 \%$ for fats in the commercial diet. Of the faecal fatty acids of pigs from these groups, $55-80 \%$ consisted of palmitic and stearic acids, as determined by gas-liquid chromatography.

\section{Serum lipids}

Total fatty acids. As shown in Tables 3 and 6, pigs on the no-fat diet (group I) and beef-tallow diet (group 2 ) had greatly increased contents of eicosatrienoic acid (20:3) $(P<0.01)$, decreased contents of linoleic $(P<0.01)$ and arachidonic $(P<0.00 \mathrm{I})$ acids and increased eicosatrienoic to arachidonic acid ratios $(P<0.025$ on $t$ test; $P<0.01$ on median test) compared with those given the maize-oil diet (group 3 ) and commercial diet (group 4). The decreased amount of linoleic acid was compensated by a corresponding increase in oleic $(P<0.001)$ and palmitoleic $(P<0.001)$ acids.

Neutral lipids. Plasma cholesterol content was variable, but the mean values were not significantly different (Table 4). The contents of total glycerides were the same in all groups.

Phospholipids. Among the groups given the semi-synthetic diets the 'beef-fat' group had the highest mean phospholipid concentration and the 'no-fat' group the lowest (Table 4). The 'beef-tallow' group was significantly different from the 'no-fat' group $(P<0.01)$, and the 'maize-oil' group was probably significantly different from the 'no-fat' group (on $t$ test $P<0$.oor; on median test, not significant); but these two groups were not significantly different from each other. However, the 'no-fat' group was unchanged compared to the commercial diet group. When the percentage composition of the serum phospholipids was determined (Tables 3,5 and 6) there was an increase in the percentage of lecithin and a decrease in that of sphingomyelin and lysolecithin in the 'no-fat' and 'beef-tallow' groups, both diets being deficient in essential fatty acid $(P<0$. 0 I for each). The effect was much greater in the 'no-fat' than in the 'beef-tallow' group. However, the concentration of lecithin in the serum of the 'no-fat' group was unchanged and the change in concentration in the phospholipids was due to decreases in the concentrations of sphingomyelin and lysolecithin.

\section{Statistical analysis}

Apart from those discussed below the results of the various statistical methods were in agreement except that the level of significance was occasionally different. The analyses which need special comment are:

In the analysis of all groups by the three tests(see p. 387 ), for lecithin concentration, test I gave $P<0.0$ I, test 2 gave $P<0.025$ and test $3 P>0.05$.

In the comparison of the 'no-fat and beef-tallow' group with the 'maize-oil and commercial diet' group, for sphingomyelin concentration, the groups were different at $\mathrm{r} \%$ on the $t$ test but not significantly different at $5 \%$ on the median test and hence we cannot be sure whether or not a significant difference existed. (The ratio of the 


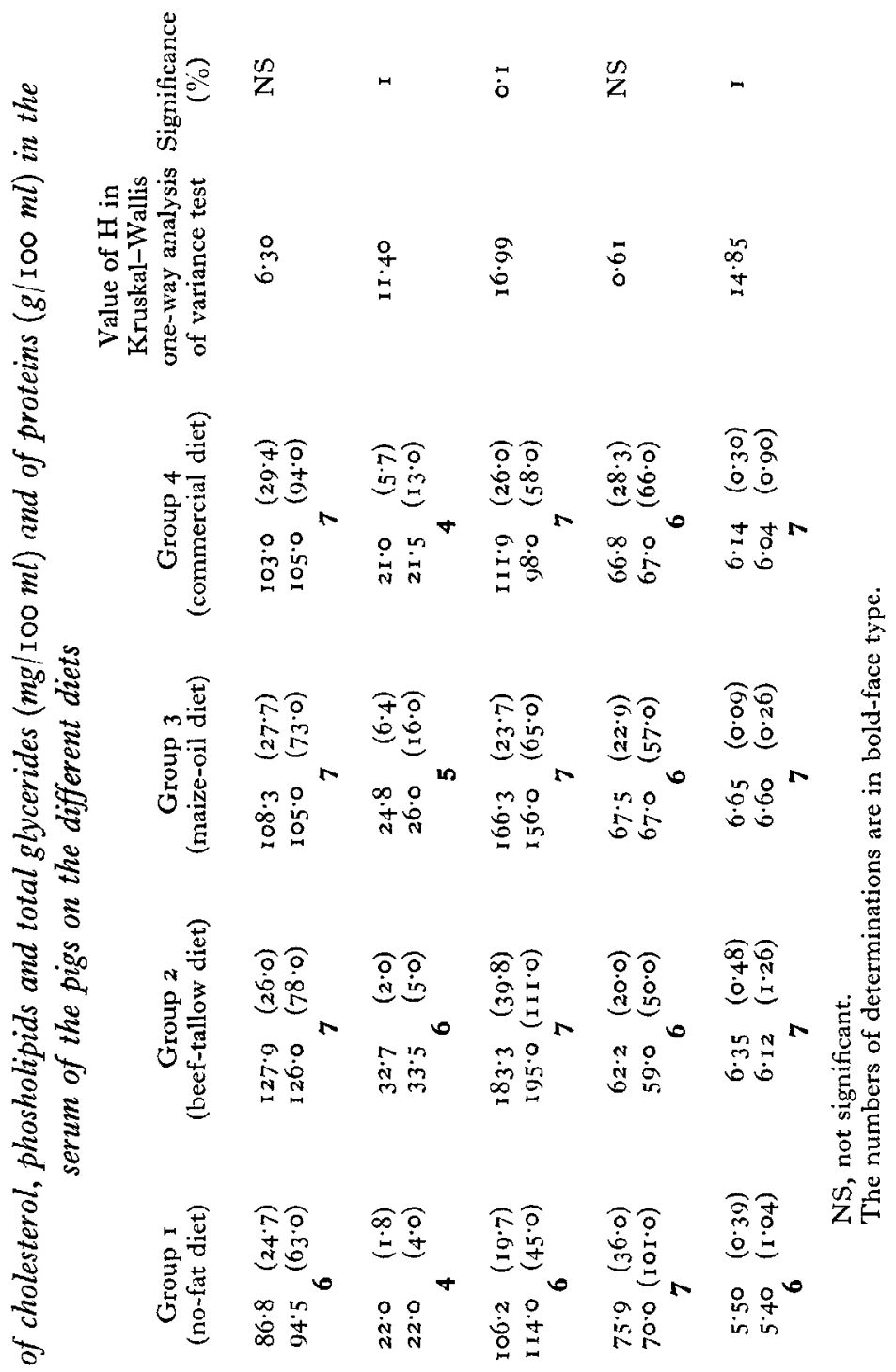

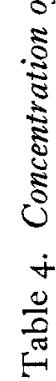

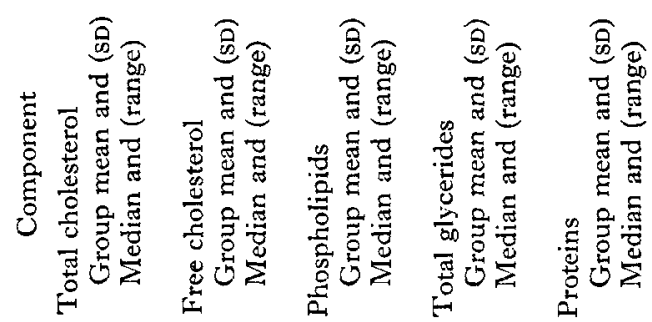




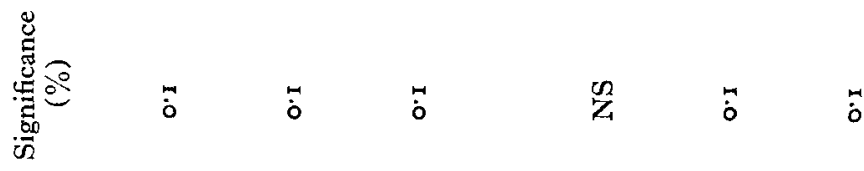

$\leqq$ 电:

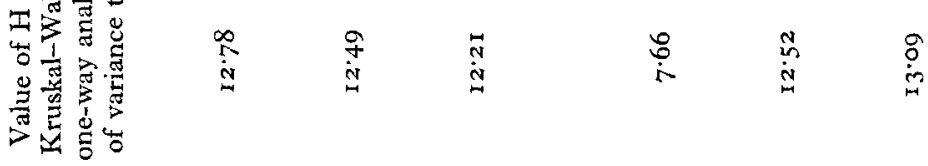

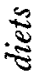

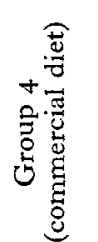

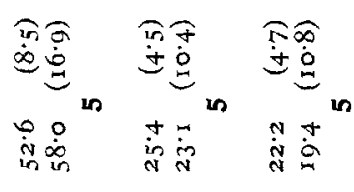

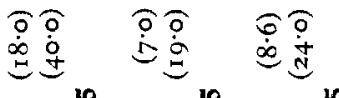

苋

$\approx$

N

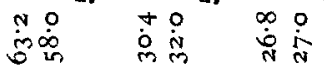

ธ

然

$\stackrel{2}{\approx}$

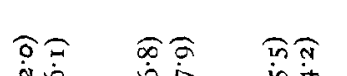

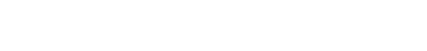

空

字

:

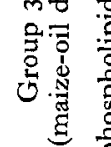

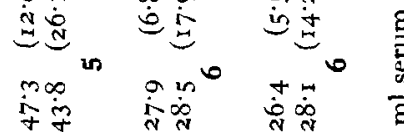

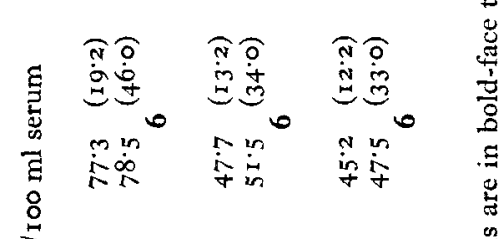

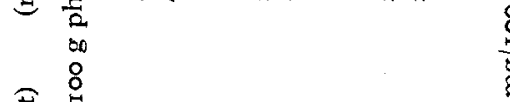

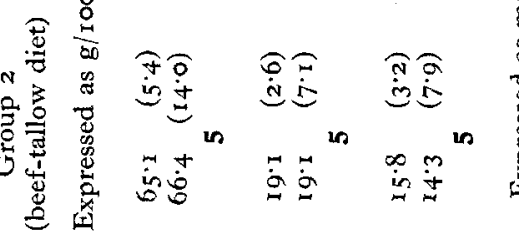

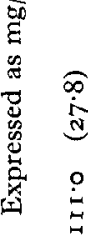

ن

in

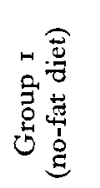

की

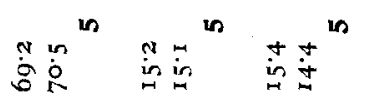

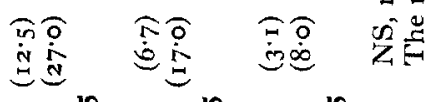

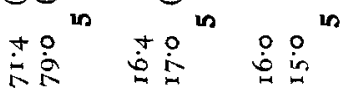

$\frac{0}{0}$

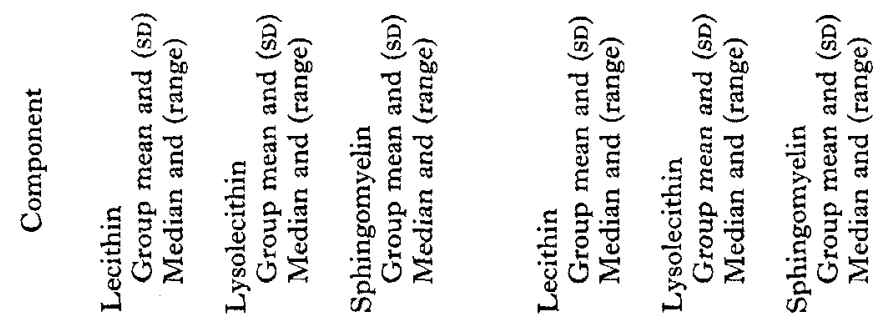


Table 6. Comparison of pooled results for the 'no-fat' and 'beef-tallow' groups of pigs with the pooled results for the 'maize-oil' and 'commercial' groups

\section{Variable}

Palmitic acid, I6:0 Group mean and (SD) Median and (range)

Palmitoleic acid, I6:I Group mean and (SD) Median and (range)

Oleic acid, I8: 1

Group mean and (SD) Median and (range)

Linoleic acid, $18: 2$ Group mean and (SD) Median and (range)

Eicosatrienoic acid, 20:3 Group mean and (SD) Median and (range)

Arachidonic acid, 20:4 Group mean and (SD) Median and (range)

Ratio, eicosatrienoic: arachidonic

Group mean and (SD)

Median and (range)

Free cholesterol ( $\mathrm{mg} / \mathrm{1} 00 \mathrm{ml}$ serum)

Group mean and (SD)

Median and (range)

'Maize-oil' and 'commercial' groups

Significance of 2-tailed median test tallow' groups

$13 \cdot 7$

13.7

$$
(1 \cdot 3)
$$

Ir

$\begin{array}{rr}15.8 & (3 \cdot 3) \\ 14.8 & (11 \cdot 2)\end{array}$

NS

$5 \cdot 9$

$5 \cdot 5$

(I.9)

(6.I)

Ir

$2 \cdot 3$

$2 \cdot 2$

(0.8)

$(2 \cdot 5)$

0.1

I2

$$
19 \cdot 6 \quad(3 \cdot 8)
$$

19.2 (II.3)

12

$\begin{array}{llr}5 \cdot 1 & & (4.3) \\ 5 \cdot 7 & & (10.4)\end{array}$

$30 \cdot 9$

$32 \cdot 3$

$(7 \cdot 9)$

$(2 \cdot 3)$

4.9
$4 \cdot 1$

$(6 \cdot 4)$

II

(I'I)

$(2 \cdot 8)$

II

10.5

$$
0.8
$$$$
0.8
$$

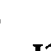

12

$(0.3)$

$(0.9)$

0.1

(1.5)

$(4 \cdot 3)$

12

O. I

$8.9 \quad(10.7)$

$\mathrm{I} \cdot 4 \quad(33 \cdot \mathrm{I})$

I I

$$
0.1 \quad(0.1)
$$

0.1

12

$23 \cdot 1$

$24 \cdot 0$

$(6 \cdot 1)$

$\left(5^{\cdot 8)}\right.$

$(14 \cdot 0)$

Phospholipids (mg/roo ml serum)

Group mean and (SD)

Median and (range)

$147 \cdot 7$
$123 \cdot 0$

Protein (g/roo ml serum)

Group mean and (SD)

Median and (range)

$5 \cdot 96$
$6 \cdot 08$

I3

$(50 \cdot 6)$

(150.0)

3

$139^{\circ} I$
$143^{\circ} \circ$

9

NS

(18.0)

$(\%)$

0.1

O' I

$(37 \cdot 0)$

$\left(123^{\circ} 0\right)$

NS

14

$6.40 \quad(0.34)$

$6.59 \quad(1.03)$

NS

14

50.0

50.9

(10.2)

$67 \cdot 2$

$67 \cdot 3$

IO

$(4.6)$
$(15.8)$

Median and (range)

$17 \cdot$

Group mean and (SD)

Median and (range)

$(3 \cdot 6)$

$(12 \cdot 7)$

$26 \cdot 8$

$27 \cdot 4$

Io

$(2 \cdot 7)$

$(8 \cdot 0)$
$15 \cdot 6$

14.4
Group mean and (sD)

Median and (range) ro 
Table 6 (cont.)

Variable
Lecithin (mg/ $100 \mathrm{ml}$ serum)
Group mean and (sD)
Median and (range)
Lysolecithin (mg/ $/ 00 \mathrm{ml}$ serum)
Group mean and (sD)
Median and (range)
Sphingomyelin (mg/roo ml serum)
Group mean and (sD)
Median and (range)

'No-fat' and 'beeftallow' groups

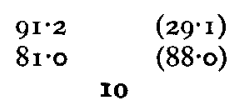

10

24.5 (II.4)

23.0 To

$2 I \cdot 5$

19.0

$(8 \cdot 3)$
$(27 \cdot 0)$
'Maize-oil' and
'commercial' groups

Significance of z-tailed median test $(\%)$

NS

$\begin{array}{ll}70.9 & (19 \cdot 2)\end{array}$

(59.0)

II
$39.8 \quad(13.7)$
$38 \cdot 0 \quad(42 \cdot 0)$
II

$\begin{array}{ll}36 \cdot 8 & (14 \cdot 0) \\ 36 \cdot 0 & (44 \cdot 0)\end{array}$ II

NS, not significant.

The numbers of determinations are in bold-face type.

variances was $2 \cdot 8$.) For the ratio $20: 3 / 20: 4$, the groups were significantly different at $2.5 \%$ on the $t$ test and at $0.1 \%$ on the median test, and so it would appear very reasonable to think that there was probably a real difference (especially since the variance ratio was $55^{\circ} 955$ ). The tests on phospholipids between the four groups, in general, gave the same results on both tests except that, in the comparison of the 'no-fat' group with the 'maize-oil' group, the significance level was $0 \cdot 1 \%$ for the $t$ test and only $5 \%$ for the median test, and hence we cannot be sure of whether a difference is likely to have existed. (The ratio of the variance was $\mathrm{I}_{4} 4$.)

\section{DISCUSSION}

Our results suggest that dietary linoleic acid is not required for growth of the pig up to about $200 \mathrm{lb}$ body-weight. Witz \& Beeson (195) reported that pigs given a semi-synthetic diet containing $0.06 \%$ fat showed a cessation of growth after $6_{3}$ days. It is difficult to reconcile these findings with ours, since our pigs were weaned on to the semi-synthetic diets earlier and were maintained on them for a longer period than the pigs used by Witz \& Beeson. Pigs given the semi-synthetic diet containing no fat or beef tallow were deficient in essential fatty acid as judged by an increase in the content of eicosatrienoic acid and a decrease in that of arachidonic acid in their serums. When given at the $10 \%$ level, beef tallow supplied at the most about $0.2 \%$ of the energy value of the diet as linoleic acid, which as judged by a triene:tetraene ratio in serum of $\mathrm{I}: 2$ is insufficient for the requirement of the pig, although adequate for growth. This value agrees well with that previously found for the pig at this level of dietary linoleate (Leat, 1962).

In general, the semi-synthetic diets described would seem suitable for nutritional work and, apart from the no-fat diet, all were palatable. The two defects noted were firstly the great thirst of the animals, which was possibly due to an imbalance (excess) of potassium and chloride both of which were present in the diets in twice the quantities required by the animal. Secondly, leg weaknesses were seen, the cause of which 
was obscure but may have been a deficiency of manganese, which was included at a level of only $\mathrm{I} \cdot 2 \mathrm{mg} / \mathrm{lb}$ diet instead of the required $18 \mathrm{mg} / \mathrm{lb}$, to a deficiency of zinc, of which there was also only one-tenth of that required, or to the incomplete absorption of the fat-soluble vitamins. The group which showed most severe leg weaknesses was the one consuming the no-fat diet.

Although the calculated digestible energy of the synthetic diets was higher than that of the commercial diet there was little difference in the final live weights. The carcasses of the pigs given the semi-synthetic diets contained a greater proportion of fat than those given the commercial diet (Leat et al. 1964). The pigs given no fat, beef tallow or maize oil had similar growth rates, which is not unexpected as the fat replaced an isocaloric weight of carbohydrate. The digestibility of beef tallow was $44 \%$ compared with $79 \%$ for maize oil, and the absence of decrease in the growth rate of pigs given the beef-tallow diet is surprising. However, this discrepancy may be explained by the fact that the pigs given the maize-oil diet had most fat in the carcass.

Differences in the serum lipids were small. In contrast to findings for the rabbit (Wigand, r960; Gresham \& Howard, 1962), the giving of a semi-synthetic diet to pigs did not increase the concentration of serum cholesterol or total glycerides. As is reported in another publication (Gresham et al. 1964), atherosclerosis seen in all groups was small and there was no difference in the extent or severity. From this aspect the results were disappointing and the principal object of the experiment, namely to induce extensive aortic atherosclerotic plaques and subject them to chemical analysis, could not be achieved. The diets used for these pigs were not identical to those used in experiments with the rabbit described above, the chief differences being the use of sucrose instead of starch as carbohydrate. It is more likely that the failure to produce hyperlipidaemia and increased atherosclerosis was due to species rather than to dietary differences.

Albrink (1962) suggests that in man a high serum triglyceride level is related to the carbohydrate content of the diet, when isocaloric diets are consumed. These chariges were not seen in pigs, since those given the diet highest in carbohydrate ('no-fat' group) had the same level of serum triglycerides as the controls ('maize-oil' and 'commercial' groups). Unlike in the rat (Alfin-Slater, Aftergood, Wells \& Deuel, I954), serum cholesterol content was not lowered by giving a low-fat diet deficient in essential fatty acids. The changes in the phospholipid concentrations were small. The chief abnormality noted was an increase in the proportion of lecithin at the expense of lysolecithin and sphingomyelin in both groups deficient in essential fatty acids. These changes are difficult to interpret, but they may be of some importance as the essential fatty acids are important constituents of pig serum lecithin (Leat, 1964). In deficiency of essential fatty acids, linoleic and arachidonic acids in lecithin are replaced by eicosatrienoic acid and the small increase may be an attempt of the organism to compensate for the lack of normal lecithin. 


\section{SUMMARY}

r. Four groups of seven pigs were given a semi-synthetic diet containing no fat, 10\% beef tallow or 10\% maize oil or a commercial diet from weaning until slaughter at about $190 \mathrm{lb}$ live weight.

2. Apart from some leg weakness, gain in weight on the semi-synthetic diets was satisfactory. Linoleic acid was apparently not required for growth of the pig up to nearly I $90 \mathrm{lb}$ live weight, all groups having the same rate of gain in weight.

3. Pigs given the diets containing no fat or beef tallow were deficient in essential fatty acids as judged by an increase in the content of serum eicosatrienoic acid and a decrease in that of arachidonic acid.

4. Differences in the concentration of serum lipids between the groups were small, and a semi-synthetic diet did not produce hypercholesterolaemia, as in the rabbit. Serum cholesterol content was lowered by $10 \%$ in the 'no-fat' group and raised by $10 \%$ in the 'beef-fat' group. No changes were observed in serum total glycerides but, in the phospholipids of these two groups, the proportion of lecithin was increased at the expense of lysolecithin and sphingomyelin.

This study was supported by a grant from the H. E. Durham Fund, King's College, University of Cambridge, and a Public Health Service Grant H-6300, National Heart Institute, Bethesda, Maryland. The technical assistance of W. Martin, M. Brown, E. Porter and Mrs J. Wilson is gratefully acknowledged. We are grateful for a generous gift of maize oil from Loder \& Nicoline Ltd, Unilever House, London.

\section{REFERENCES}

Albrink, M. J. (1962). Arch. intern. Med. ro9, 345.

Alfin-Slater, R. B., Aftergood, L., Wells, A. F. \& Deuel, H. J. Jr. (1954). Arch. Biochem. Biophys. 52, I 80 .

Allen, R. J. L. (1940). Biochem. $\mathcal{F} .34,858$.

Crawford, N. (1958). Clin. chim. Acta, 3, 375.

Gresham, G. A. \& Howard, A. N. (1962). Arch. Path. 74, I.

Gresham, G. A., Leat, W. M. F., Howard, A. N. \& Jennings, I. W. (1964). Brit. F. exp. Path. 45, I 28. Hooghwinkel, G. J. M. \& van Niekerk, H. P. G. A. (I960). Proc. Acad. Sci. Amst. 83 B, 469.

James, A. T., Webb, J. P. W. \& Kellock, T. D. (196I). Biochem. 7. 78, 333.

Kendall, M. G. (195I). The Advanced Theory of Statistics. Vol. 2, p. 113. London: Charles Griffin and Co.

Lambert, M. \& Neish, A. C. (I950). Canad. F. Res. Sect. B, 28, 83.

Leat, W. M. F. (1962). Brit. $\mathcal{F}$. Nutr. 16, 559.

Leat, W. M. F. (1964). Biochem. Y. 91, 437.

Leat, W. M. F., Cuthbertson, A., Howard, A. N. \& Gresham, G. A. (I964). F. agric. Sci. 63, 3 I I.

Marinetti, G. V., Erbland, J. \& Kochen, J. (1957). Fed. Prac. r6, 837.

Siegel, S. (1956). Nonparametric Statistics for the Behavioral Sciences, p. 183. New York: McGraw-Hill Book Co. Inc.

Sperry, W. M. \& Webb, M. (1950). J. biol. Chem. 187, 97.

Van Handel, E. \& Zilversmit, D. B. (1957). F. Lab. clin. Med. 50, 152.

Wigand, G. (1960). Acta med. scand. Suppl. 35 I.

Witz, W. M. O. \& Beeson, W. M. (1951). F. Anim. Sci. то, г12.

Woodman, H. E. \& Evans, R. E. (195I). F. agric. Sci. 41, Ioz.

Zlatkis, A., Zak, B. \& Boyle, A. J. (I953). F. Lab. clin. Med. 41, 486. 